\section{Forest stand height determination from low point density airborne laser scanning data in Rožňava Forest enterprise zone (Slovakia)}

\author{
Róbert Smreček $^{(1)}$, Zuzana Danihelová ${ }^{(2)}$
}

The presented paper discusses the potential of low point density airborne laser scanning (ALS) data for use in forestry management. Scanning was carried out in the Rožňava Forest enterprise zone (Slovakia) with a mean laser point density of 1 point per $3 \mathrm{~m}^{2}$. Data were processed in SCOP++ using the hierarchic robust filtering technique. Two DTMs were created from airborne laser scanning (ALS) and contour data and one DSM was created using ALS data. For forest stand height, two normalised DSMs (nDSMs) were created by subtraction of the DSM and DTM. The forest stand heights derived from these nDSMs and the application of maximum and mean zonal functions were compared with those contained in the current Forest Management Plan (FMP). The forest stand heights derived from these data and the application of maxima and mean zonal functions were compared with those contained in the current FMP. The use of the mean function and the contour-derived DTM resulted in forest stand height being underestimated by approximately $3 \%$ for stands of densities $\mathbf{0 . 9}$ and 1.0 , and overestimated by $6 \%$ for a stand density of 0.8 . Overestimation was significantly greater for lower forest stand densities: $81 \%$ for a stand density of 0.0 and $37 \%$ for a density of 0.4 , with other discrepancies ranging between 15 and $30 \%$. Although low point density ALS should be used carefully in the determination of other forest stand parameters, this low-cost method makes it useful as a control tool for felling, measurement of disaster areas and the detection of gross errors in the FMP data. Through determination of forest stand height, tree felling in three forest stands was identified. Because of big differences between the determined forest stand height and the heights obtained from the FMP, tree felling was verified on orthoimages.

Keywords: Airborne Laser Scanning, Low Point Density, Forestry, Forest Stand Height

\section{Introduction}

Airborne laser scanning (ALS) is an active remote sensing technique based on the transmission of laser impulses to the Earth's sur-

(1) Department of Forest Management and Geodesy, Technical University in

Zvolen, T. G. Masaryka 24, 96053 Zvolen (Slovakia); (2) The Institute of Foreign Languages, Technical University in Zvolen, T. G. Masaryka 24, 96053 Zvolen (Slovakia)

(a) Róbert Smreček

(robert.smrecek@tuzvo.sk)

Received: Sep 07, 2012 - Accepted: Dec 05, 2012

Citation: Smreček R, Danihelová Z, 2013.

Forest stand height determination from low point density airborne laser scanning data in Rožňava Forest enterprise zone (Slovakia). iForest 6: 48-54 [online 2013-01-21] URL: http://www.sisef.it/iforest/contents? id=ifor0767-006

Communicated by: Marco Borghetti
Box 1 - List of abbreviations.

ALS: Airborne laser scanning LiDAR: Light Detection and Ranging RADAR: Ratio Detection and Ranging DTM: Digital terrain model DSM: Digital surface model nDSM: Normalised digital surface model nDSM_L: DTM created from ALS data was used for nDSM creation

nDSM_C: DTM created from contour data was used for $\mathrm{nDSM}$ creation

FMP: Forest management plan

WMP: Web Map Service

FOV: Field of view

GPS: Global positioning system

IMU: Inertial measurement unit

ved through a series of profile measurements in the direction perpendicular to the flight line. Using a series of profiles measured in the cross-track direction, the position and elevation of a mesh of points, also called a point cloud, is generated (Petrie \& Toth 2009). Parameters, such as the density of points (no. of points per $\mathrm{m}^{2}$ ), the spacing between points (average point spacing), footprint of laser impulse and number of echoes, are used to describe the point cloud. These parameters have an influence on the applicability of ALS data and the output from applications in which ALS data are used.

The density of points and spacing between points affects the detail of object reconstruction from ALS data, e.g., buildings, terrain, trees and the minimum resolution of objects. The density of points and also spacing between points vary throughout the data and generally are greater in areas where ALS strips overlap.

face. The system measures the round-trip time taken for a laser impulse to travel between the sensor and target, during which time the impulse interacts with both objects (tree crowns, buildings, etc.) and the ground surface before being reflected back to the system. The travel time of the impulse, from transmission until return, can therefore be taken as a representation of the distance (or range) between instrument and object. External orientation is continuously recorded using satellite navigation and internal aircraft systems. The technique is also known as LiDAR (Light Detection and Ranging), since ALS instruments operate on the same principle as RADAR (Ratio Detection and Ranging) instruments by sending out short laser impulses and measuring the time delay of backscattered echoes for range determination (Jenn 2005). As with side-looking RADARs, ALS sensors can record the strength of these backscattered echoes in order to construct images of the surveyed area (Wagner 2010).

In the case of ALS, area scanning is achie-
Points are classified by density. High point density is where the density is higher than 10 points per $\mathrm{m}^{2}$ and low point density is where the density is below 1 point per $\mathrm{m}^{2}$. If the density is greater than 50 points per $\mathrm{m}^{2}$, it is classified as very high. Due to current laser scanner technology, trends in applications and users requirements, a density classification below 1 point per $\mathrm{m}^{2}$ is not necessary.

Initially it was expected that laser scanning would pose serious competition to photogrammetry. In their comparison of the two methods, Hollaus et al. (2005) described ALS as being characterized by point scanning, whereas photogrammetry provides full coverage of an area. Photogrammetry is also a passive method of remote sensing and is thus highly dependent on the weather. The basic advantages of photogrammetry are that the produced images can contain both spectral and textual information, can cover a very high positional precision, as well as the fact that objects in these images can potenlarge area, have high spatial resolution and 
tially be directly identified and measured. It is also possible to create orthophotos and digital terrain models (DTMs) using data obtained via photogrammetry. The disadvantages of the technique include an inability to see beneath tree cover, the fact that for stereoscopic analysis the target must be visible from two different places and the large period of time typically required for image interpretation. ALS has a number of advantages, such as the simple geometry of measurement and that a $3 \mathrm{D}$ point position on a surface can be measured from a single position. In addition, high point density ALS allows the creation of highly accurate digital surface models (DSMs) and DTMs. ALS is also capable of mapping an area with little or no texture, while laser data processing can be highly automated. However, as Tuček (2001) stated, although laser scanning provides a high density of points, it is not able directly capture fault lines, object edges and so on, unlike the manner in which photogrammetry captures object information. Aerial images are also able to provide all information regarding objects located within areas between dividing lines. As a result of these differences between the two technologies, many authors (e.g., Ackerman 1999, Persson et al 2004, Baltsavias 1999, Hollaus et al. 2005) advise the use of combined data from photogrammetry and laser scanning, ideally both recorded using small time intervals.

The attributes most commonly used to describe forest stands include age, number of trees per hectare, mean diameter, basal area per hectare, mean height, dominant height, Lorey's mean, volume per hectare, mean form factor, current annual increment per hectare, mean annual increment per hectare and growth. Some of these can be calculated via direct measurement, whereas others can only be estimated through statistical or physical modeling. ALS was first employed in forest analysis for, amongst other things, the determination of terrain elevation, standwise mean height and volume estimation, individual-tree-based height determination and volume estimation, measurement of forest growth and the detection of harvested trees (Hyyppä et al. 2009). The advantage of ALS - verified in many scientific papers (e.g. Naesset 1997, Ziegler et al. 2000, Wack et al. 2003, Andersen \& Breindenbach 2007 Korpela et al. 2007) - in comparison to classic methods of forest inventory is its ability to quickly obtain information with a high degree of automation. Wood species classification is also possible via the use of ALS data (Brandtberg et al. 2003, Liang et al. 2007, Orka et al. 2007).

Initial applications of ALS in forestry were largely focused on the determination of stand and tree height, although different methods must be employed for the two calculations. Determination of forest stand or plot height is necessarily based on canopy surface (Andersen et al. 2005, Coops et al. 2007, Wezyk et al. 2008, Naesset 2009), whereas that of single tree height is associated with point cloud segmentation (Naesset \& Okland 2002, Morsdorf et al. 2004, Heurich 2008, Popescu \& Zhao 2008). Unlike classical measurement via hypsometer, in which determination of tree/stand height is more problematic than that of breast height diameter $\left(d_{1.3}\right)$, the determination of $d_{1.3}$ using ALS data is more difficult than that of height or crown diameter. As a result, several models aimed at estimating values of $d_{1.3}$ from the height derived from ALS data have been created (e.g., Anderson et al. 2008, Dean et al. 2009, Salas et al. 2010).

The aim of this paper is to present the potential for using ALS data of low point density for forest stand height determination. The determination of forest stand height was done through the subtraction of DSM and two DTMs created from ALS data and from $20 \mathrm{~m}$ contours. The determined forest stand height was compared with the heights from the Forest Management Plan. The benefit of this paper is from the use of low point density ( 1 point per $3 \mathrm{~m}^{2}$, or 0.33 point per $\mathrm{m}^{2}$ ) in comparison with other studies. Less than 1 point per $\mathrm{m}^{2}$ was used in studies by Coops et al. (2007), $0.7 \mathrm{p} / \mathrm{m}^{2}$; Korpela et al. (2007), $0.7-2 \mathrm{p} / \mathrm{m}^{2}$ and Naesset (2009), $0.8 \mathrm{p} / \mathrm{m}^{2}$. Most authors use point density between 1 and $10 \mathrm{p} / \mathrm{m}^{2}$ (Ziegler et al. 2000, Andersen et al. 2005, Andersen \& Breindenbach 2007, Liang et al. 2007, Popescu \& Zhao 2008, Wezyk et al. 2008, Dean et al. 2009, Salas et al. 2010, Clementel et al. 2012). ALS data with point density of $10 \mathrm{p} / \mathrm{m}^{2}$ and more was used in the studies of Morsdorf et al. (2004), $10 \mathrm{p} / \mathrm{m}^{2}$ and Brandtberg et al. (2003) $12 \mathrm{p} / \mathrm{m}^{2}$ by using layer with echo 1 .

\section{Material}

ALS data were provided by Geodis Slovakia s.r.o., covering the Rožňava Forest enterprise zone (Slovakia) in summer 2009. The airborne laser scanner employed was a Leica ALS 50-II, with a flight altitude of $3750 \mathrm{~m}$ and a $50^{\circ}$ field of view (FOV). The average density of laser points was 1 point per $3 \mathrm{~m}^{2}$, representing an average distance between points of $1.5-2 \mathrm{~m}$. The area was scanned in four full strips and a part of the fifth strip, providing data that are overlapped with the fourth strip data. During the same flight a series of $25-\mathrm{cm}$ resolution aerial images was taken of the study area, using an UltraCamXp large format digital aerial camera.

Relevant data from the Slovakian national Forest Management Plan (FMP) were provided by the National Forest Center, including age, tree species composition and height of forest stands. The FMP has been valid since 2009 . The field measurements were done during year 2008. In addition, the
Web Map Service (WMS) of the National Forest Center was used to obtain 20-m contours of the study area for DTM creation.

The tree height in the FMP is represented by the medium height of a tree species. The medium height of a tree species is a dendrometric parameter, which indicates the height of a tree with an average width, volume, or basal area. In describing the forest stand, this is determined as the arithmetic average of measurements realized in forest stands on sample plots in different locations, for estimated mean trees. The height is measured to a precision of one meter. In removal stands, for the calculation of stock using yield tables (substitute the direct measurement), the height is rounded to a tenth of a meter (Bavlšík et al. 2008).

\section{Methods}

\section{Hierarchic robust filtering}

The hierarchic robust filtering technique employed in this study was implemented using the commercial software package $\mathrm{SCOP}++$, a joint development of the photogrammetric systems supplier Inpho, Germany, and the Institute of Photogrammetry and Remote Sensing of Vienna University of Technology, Austria. SCOP++ is designed to efficiently handle DTM projects of any size, using data derived from ALS, photogrammetry or any other source. SCOP++ is also designed for the interpolation, management, application and visualization of digital terrain data, with an emphasis on accuracy.

The hierarchic filtering strategy comprises four different processing steps referred to as ThinOut, Interpolate, Filter and SortOut. These four steps can be applied consecutively, with few rules restricting the order of application or the number of iterations. The sequence of the hierarchic robust filtering technique is shown in Fig. 1. ThinOut refers to a raster-based thinning algorithm which lays a grid over the complete data domain and selects one point (e.g., the lowest) for each cell. During the Interpolate step, a terrain model is derived from the current data set via interpolation, without differentiating data points. A terrain model is also computed during the FiLTER step, but this time a weighting function designed to give low computational weight to likely off-terrain points and high weight to likely terrain points is applied. In the SORTOUT step, only data points within a certain distance from a previously calculated DTM are retained. Depending on the characteristics of the ALS data set, different filtering strategies can be devised. The flexibility in the design of the strategy, combined with the possibility of selecting a number of parameters at each processing step, has the advantage that satisfactory results can be achieved without the need for manual editing, with the exception of a 
Fig. 1 - Sequence of the hierarchic robust filtering technique (source: Briese et al. 2002). (A): Creation of a low resolution data pyramid; small points - original data, thick points - data pyramid

(lowest point in the grid).

(B): DTM generation at coarse level via robust interpolation. The surface at the

first and last iteration is shown. (C): Coarse DTM with a tolerance band; all original points within the tolerance band are accepted. (D): DTM generation at fine level via robust interpolation using an asymmetric and shifted weight function. The first and last iterations are shown.

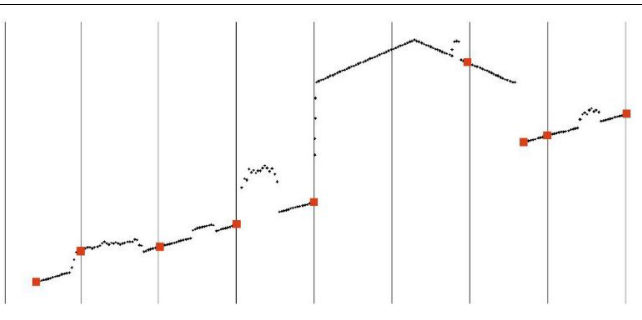

(A)

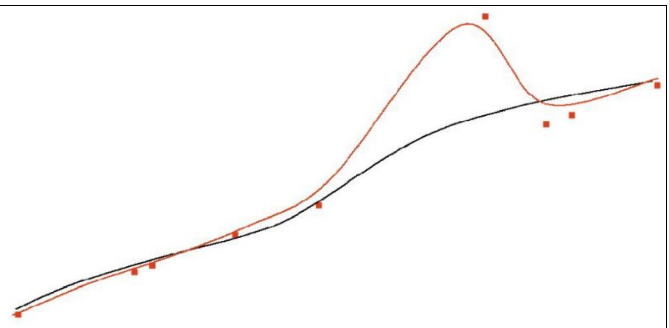

(B)
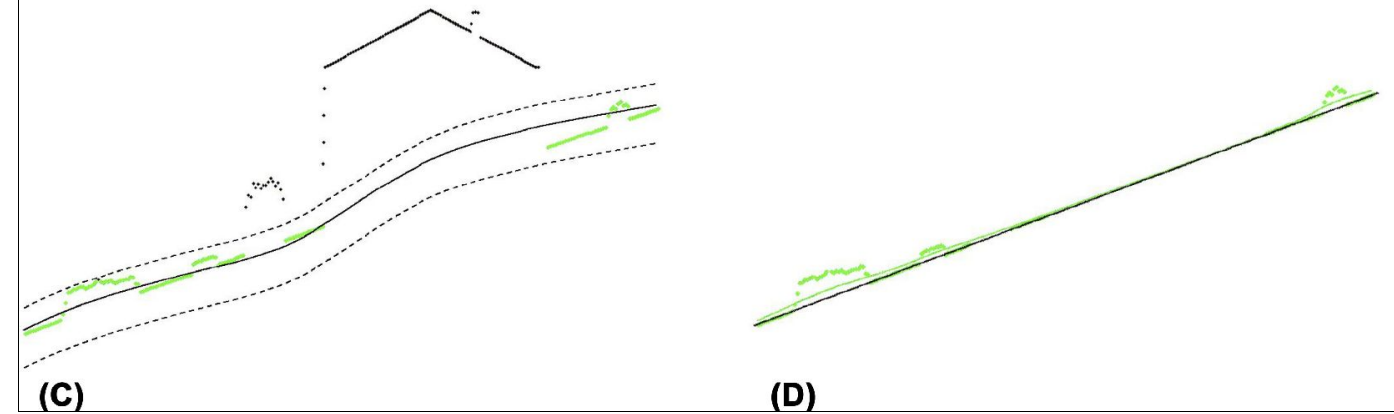

few problem areas. The most significant disadvantage of the method is that it is difficult to predict how changes in the filtering strategy or parameter setting will affect the final DTM (Wagner et al. 2004).

The main feature of hierarchical robust interpolation is the creation of a data pyramid representing the data at different resolution levels. Three steps are carried out at each level of the pyramid (Bauerhansl et al 2004):

- thinning out of the original data according to the resolution of the current level of the data pyramid, using only points not yet classified as being off-terrain,

- generation of a DTM via robust interpolation, using the thinned-out data,

- comparison of the generated DTM with the original data. Data points outside a certain tolerance band are classified as off-terrain and are thus no longer considered in the subsequent iterations.

At the finest level, the DTM is computed from all original points classified as terrain points. Using thinned-out data, the influence of large clusters of off-terrain points (e.g. points on buildings) can be eliminated, but the resulting DTM also has a rather coarse resolution. The influence of low vegetation is eliminated using the data at a finer resolution, a process that also results in a better DTM (Bauerhansl et al. 2004).

\section{DTM and DSM creation}

To derive the DTM, due to the need for points at ground level, the area should preferably not be scanned during the growing season, as the presence of vegetation decreases laser impulse penetration to the ground. In contrast, for DSM derivation the growing season is more appropriate, since more laser impulses are reflected from the crowns of trees (deciduous more so than evergreen) and low vegetation. Scanning data obtained during the growing season is largely used to determine the height of vegetation cover (Wagner et al. 2004).

The ALS data used in the present study were obtained during the growing season. As stated above, the creation of DTMs from data collected at this time of year is problematic, because laser impulses do not penetrate effectively through the dense vegetation cover, resulting in absent ground points in DTM creation. Another problem associated with the processing of ALS data is the use of a filtering method and its ability to correctly classify points on the surface. Despite the availability of powerful filtering tools, around $1 \%$ of points are always incorrectly classified (INPHO 2009); these points should be reclassified either manually or by changing the filtering parameters.

Two DTMs were created, one from ALS and the other from contour data, but both at $8 \mathrm{~m}$ resolution. An $8 \mathrm{~m}$ spatial resolution was selected as the lowest spatial resolution for the DTM derived from the ALS data. A lower resolution would approach the errors of the DTM due to the low point density. The first DTM was created in SCOP++ using hierarchic robust filtering, with the EliminateBuildings step first applied, followed by ThinOut, Filter, Interpolate and SortOut. These last four steps were applied three times in order to efficiently filter offterrain points, before the final CLASSIFY step. In the last iteration the step SortOut was missed. Incorrectly classified points were repaired in DTMaster (Inpho), which is de- signed for the efficient quality control of DTM and LiDAR data.

The second DTM was created from vectorized 20-m contours obtained from the WMS of the Slovakian National Forest Center, using ARCMAP 10. Also vectorized were hills, which were used to refine the DTM. The DTM itself was created using the Topo то RASTER tool, which is an interpolation method designed for the creation of hydrologically correct DTMs.

The DSM was created from ALS data using hierarchic robust filtering in SCOP++, with a resolution of $8 \mathrm{~m}$. The creation of the DSM was easier than that of the DTMs, as points reflected from tree crowns were used; since the laser scanning was performed during the growing season, there were more points reflected from crowns than from the ground. In addition, it was also not necessary to filter off-terrain points. DSM hierarchic robust filtering was performed in three steps: ThinOut, Filter and Interpolate. Incorrectly classified points were repaired in DTMaster. Examples of hill-shading in the first DTM and the DSM are shown in Fig. 2.

\section{Forest stand selection}

Forest stands older than 80 years of age were selected from the FMP database. The goal was to have mostly forest stand of an exploitable age in the selection. The second selection criterion was that species representation had to be $100 \%$ in each forest stand. Some 43 forest stands were selected based on these two criteria, with two species, beech (Fagus sylvatica L.) and spruce (Picea abies Karst.), covering a total area of 101 ha. Stand density ranged between 0 and 1.0 , although none had densities of $0.1,0.2$ 

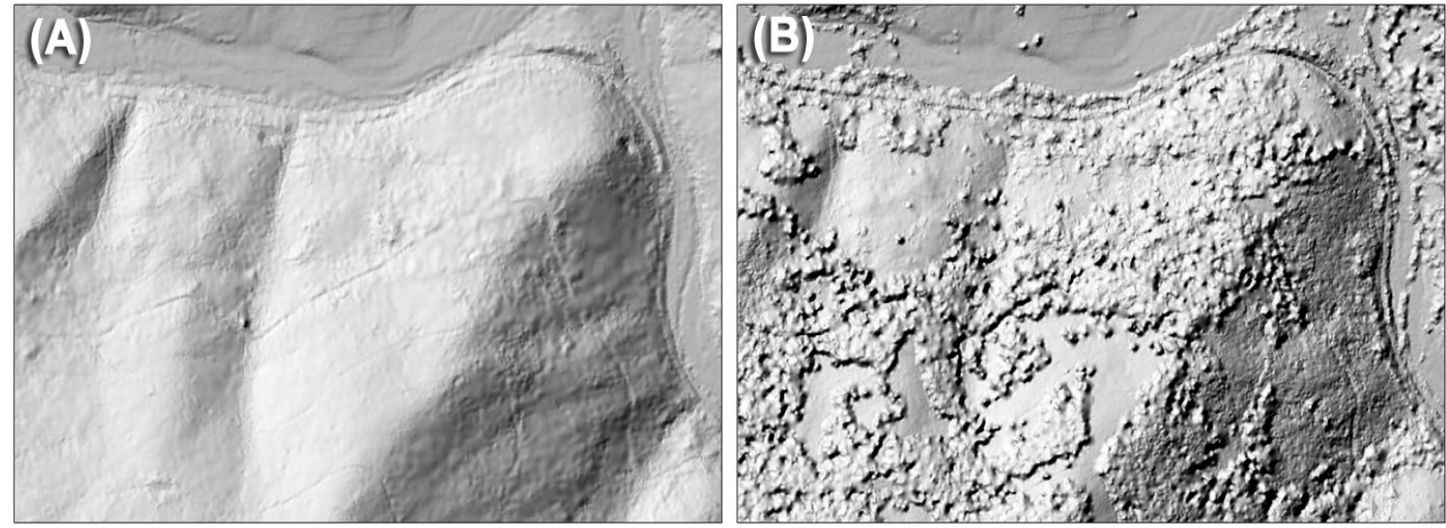

Fig. 2 - (A) DTM hillshading; (B) DSM hillshading. Data: LaserScan (C) Geodis Slovakia, s.r.o. - http://www.geodis.sk and 0.3 . The stand density was examined against the Forest Management Plan. Stand density is a relative measure of the length of stand occupancy by trees, as well as of the utilization of forest production; a low stand density is therefore detected after regeneration/replanting, natural disaster, etc.

\section{Forest stand height extraction}

Since the DTMs represent the height of terrain and the DSM the height of objects (tree tops, buildings, etc.) above the sea level, the actual height of these objects can be calculated by subtracting the former from the latter. This method, after evaluation of input data, was employed to create two normalized digital surface models (nDSMs - Fig. 3), one using the DTM created from ALS data (nDSM_L) and the other using the DTM created from contour data (nDSM C). The cell size of both nDSMs was $8 \mathrm{~m}$, with the cell value representing the height of trees in forest stands, as well as the height of buildings and other objects.

For forest stands meeting the selection cri- terion, zonal statistics were employed using ARCMAP 10 to derive mean and maximum stand height values. The mean or maximum forest stand height was extracted using zonal statistics from the pixel values of nDSM_L and nDSM C. Polygonal masks were used polygons to represent the borders of the selected forest stands. From these values were subtracted heights contained in the FMP database used as reference data. As forest stands varied in terms of their age and site quality, the difference between the FMP and ALS-derived heights was converted into a percentage.

A one-way analysis of variance (ANOVA) was then applied to determine the influence of tree species and stand density on tree height.

\section{Results and discussion}

Forest stand heights derived using ALS maxima were overestimated, both in nDSM L and nDSM C. The use of mean values largely led to an underestimation of stand height. In forest stands with the

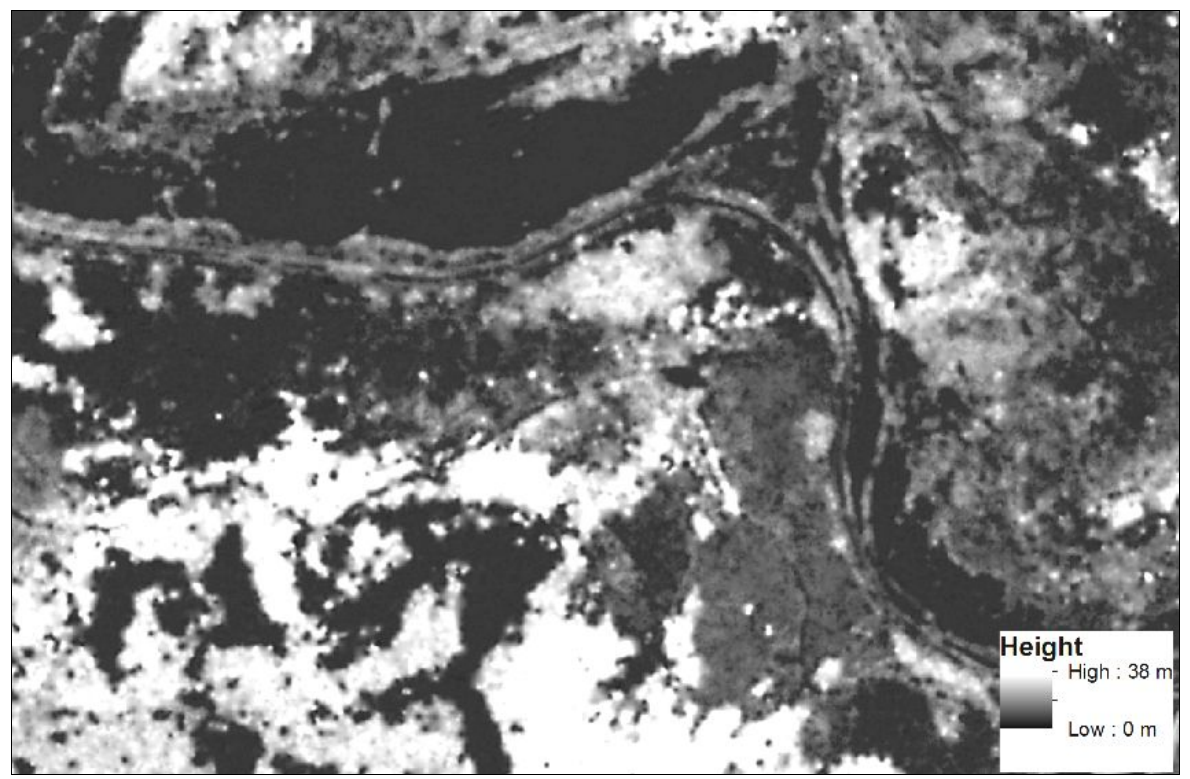

Fig. 3 - nDSM (nDSM L) created using the ALS data-derived DTM. Data: LaserScan (C)

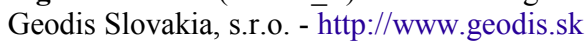

highest stand density, the forest stand height was overestimated; this occurred in three cases.

The heights of three forest stands with a density of 0.7 differed considerably in terms of the values observed in the FMP database and those derived via ALS; these differences were 97,87 and $77 \%$ for nDSM L and 84 , 107 and $65 \%$ for nDSM_C. Consultation of orthoimages revealed these discrepancies to be a result of recent tree felling, and thus these three stands were excluded from further analysis.

The influence of tree species on ALS-derived stand height was expected to be statistically significant in all cases. However, such significance was only observed after using the mean for forest stand height extracted from both nDSMs: nDSM L and nDSM_C. The reason for the lack of statistical significance when maxima were employed is unknown. Tab. 1 shows that stand heights derived from ALS maxima were nearer to FMP values for beech than for spruce, whereas Tab. 2 shows that better results for spruce than for beech were obtained when mean height values were used. One possible explanation for this is that beech crowns are more spherical and those of spruce cone-like; as a result, more points in the point cloud reflected from such spheres are closer to the top of the crown (i.e., max. height).

As shown in Tab. 4, the influence of stand density was statistically significant when mean was used for forest stand height extraction from both nDSMs; $\mathrm{nDSM} \mathrm{L}$ and nDSM_C. Although stand heights were generally underestimated, the heights of stands of density 1.0 were overestimated in nDSM_L and those of density 0.9 and 1.0 overestimated in nDSM C. Tab. 4 also shows a significant difference (underestimation) between FMP and ALS-derived mean heights for low density stands (0.0 and 0.4$)$, with values of 77 and $45 \%$, respectively, for nDSM_L, and 81 and $37 \%$, respectively, for nDSM_C. These discrepancies were likely caused by the reflection of laser impulses from suppressed trees, low vegetation and 
Tab. 1 - Overview of statistical characteristics for tree species: FMP-max (in \%).

\begin{tabular}{lcccc}
\hline \multirow{2}{*}{ Tree species } & \multicolumn{2}{c}{ Arithmetic mean } & \multicolumn{2}{c}{ Standard deviation } \\
\cline { 2 - 5 } & $\begin{array}{c}\text { ALS } \\
\text { FMP - max }\end{array}$ & $\begin{array}{c}\text { Contours } \\
\text { FMP - max }\end{array}$ & $\begin{array}{c}\text { ALS } \\
\text { FMP -max }\end{array}$ & $\begin{array}{c}\text { Contours } \\
\text { FMP -max }\end{array}$ \\
\hline Beech & -16.3 & -13.3 & 20.1 & 23.2 \\
Spruce & -19.6 & -31.3 & 13.8 & 19.9 \\
Total & -17.2 & -18.3 & 18.5 & 23.6 \\
\hline
\end{tabular}

Tab. 2 - Overview of statistical characteristics for tree species: FMP-mean (in \%).

\begin{tabular}{lcccc}
\hline \multirow{2}{*}{ Tree species } & \multicolumn{2}{c}{ Arithmetic mean } & \multicolumn{2}{c}{ Standard deviation } \\
\cline { 2 - 5 } & $\begin{array}{c}\text { ALS } \\
\text { FMP - mean }\end{array}$ & $\begin{array}{c}\text { Contours } \\
\text { FMP - mean }\end{array}$ & $\begin{array}{c}\text { ALS } \\
\text { FMP - mean }\end{array}$ & $\begin{array}{c}\text { Contours } \\
\text { FMP - mean }\end{array}$ \\
\hline Beech & 50.1 & 54.5 & 35.0 & 42.3 \\
Spruce & 19.0 & 11.7 & 17.2 & 12.7 \\
Total & 41.5 & 42.7 & 33.9 & 41.3 \\
\hline
\end{tabular}

the ground surface. For stands of density 0.6 and higher, stand heights were relatively well described using mean values both in nDSM_L and nDSM_C.

The use of maxima values resulted in fairly good estimation of stand height for stands of low density, in both nDSM_L and nDSM_C. For stands of density 0.0 , overestimation was under $8 \%$, whereas the results for those of density 0.4 were comparable with those of higher densities (Tab. 3).

The transmission of laser impulses through the canopy is not so effective in forest stands

of high density. DTMs which are unable to record the terrain under forest stands will clearly have a negative influence on stand height derivation; this effect is particularly evident in the modeling of stands with densities of 0.9 and 1.0. The determination of forest stand height using the DTM created from low point density ALS data was reported by Smreček (2012). The DTM created from contour lines was able to describe such terrain more accurately than that created using ALS data (Tab. 4).

The results achieved in the present study

Tab. 3 - Overview of statistical characteristics for stand density: FMP-max (in \%).

\begin{tabular}{lcccc}
\hline \multirow{2}{*}{ Stand density y } & \multicolumn{2}{c}{ Arithmetic mean } & \multicolumn{2}{c}{ Standard deviation } \\
\cline { 2 - 5 } & $\begin{array}{c}\text { ALS } \\
\text { FMP - max }\end{array}$ & $\begin{array}{c}\text { Contours } \\
\text { FMP - max }\end{array}$ & $\begin{array}{c}\text { ALS } \\
\text { FMP - max }\end{array}$ & $\begin{array}{c}\text { Contours } \\
\text { FMP - max }\end{array}$ \\
\hline 0.0 & -6.9 & -7.4 & 20.2 & 20.7 \\
0.4 & -22.3 & -38.2 & 7.6 & 7.6 \\
0.5 & -32.6 & -28.2 & 22.9 & 35.6 \\
0.6 & -26.1 & -2.6 & 2.9 & 18.8 \\
0.7 & -20.4 & -21.9 & 14.5 & 23.8 \\
0.8 & -24.5 & -34.9 & 1.3 & 5.8 \\
0.9 & -21.5 & -39.4 & 9.5 & 6.6 \\
1.0 & -32.4 & -26.2 & - & - \\
Total & -17.2 & -18.3 & 18.5 & 23.6 \\
\hline
\end{tabular}

Tab. 4 - Overview of statistical characteristics for stand density: FMP-mean (in \%).

\begin{tabular}{lcccc}
\hline \multirow{2}{*}{ Stand density } & \multicolumn{2}{c}{ Arithmetic mean } & \multicolumn{2}{c}{ Standard deviation } \\
\cline { 2 - 5 } & $\begin{array}{c}\text { ALS } \\
\text { FMP - mean }\end{array}$ & $\begin{array}{c}\text { Contours } \\
\text { FMP - mean }\end{array}$ & $\begin{array}{c}\text { ALS } \\
\text { FMP - mean }\end{array}$ & $\begin{array}{c}\text { Contours } \\
\text { FMP - mean }\end{array}$ \\
\hline 0.0 & 76.9 & 80.6 & 15.1 & 26.3 \\
0.4 & 45.3 & 37.1 & 35.1 & 37.3 \\
0.5 & 25.3 & 28.1 & 14.1 & 62.9 \\
0.6 & 12.6 & 22.7 & 10.5 & 14.2 \\
0.7 & 17.2 & 16.6 & 17.4 & 12.4 \\
0.8 & 4.1 & 6.4 & 0.1 & 3.4 \\
0.9 & 11.5 & -2.3 & 12.6 & 6.4 \\
1.0 & -8.5 & -3.6 & - & - \\
Total & 41.5 & 42.7 & 33.9 & 41.3 \\
\hline
\end{tabular}

were less accurate in comparison to those achieved by other authors. The most likely reason for this is the low density of points, particularly under trees, obtained for DTM creation. Wezyk et al. (2008) used two different tree crown surfaces, derived in the Fusion software program, to determine tree height. The first crown surface was subjected to arithmetic average and smoothing filters, while maximum and minimum values were neglected. In this case, actual measured tree heights were underestimated by about $0.9 \mathrm{~m}$, with a standard deviation of 1.77. Application of the second type of crown surface included the use of maxima and minima, resulting in an underestimation of only $0.12 \mathrm{~m}$, with a standard deviation of 1.81 . Heurich (2008) compared the characteristics of 0.10.25 ha beech and spruce stands in the Bavarian National Park. The mean deviation between ALS-derived height and terrain measurement was $-0.54 \mathrm{~m}$, with the difference lower $(-0.43 \mathrm{~m})$ for deciduous trees and higher $(-0.63 \mathrm{~m})$ for coniferous trees. In their examination of spruce stands, Naesset \& Okland (2002) achieved a standard deviation of tree height determination of $0.49 \mathrm{~m}$, representing $7.6 \%$ of tree height. Holmgren et al. (2003) used linear regression functions to predict basal-area-weighted mean tree height, achieving a Root Mean Square Error (RMSE) of 1.45-1.56 m, corresponding to $10-11 \%$ of mean height. Many other authors have also found that the employment of ALS typically leads to an underestimation of tree height due to the fact that laser impulses are not reflected from the majority of tree terminals (Coops et al. 2007, Heurich 2008, Wezyk et al. 2008). However, the methods used in some other studies resulted in height overestimation. For example, Lim et al. (2001) experienced a differential of $77 \%$, whereas Farid et al. (2006) overestimated the height of young cottonwood (Populus fremontii S. Watson) and mesquite (Prosopis velutina Woot.), although the latter authors believed their discrepancy in results to be caused by the reflection of laser impulses from nearby higher trees.

\section{Conclusion}

Despite the steady development of ALS which took place during the 1970s and 1980 s, the technique remains limited in that elevation data can only be acquired along a single line (i.e., the flight path). If a large area of terrain is to be covered, an accordingly large number of flights must be accomplished in order to provide complete coverage (Petrie \& Toth 2009). One of the first successful applications of laser scanning took place in the field of water depth detection, with water depth calculated as the difference between the time of first (water surface) and second (water body bed) reflections (Lillesand et al. 2008). Suitable scan- 
ning mechanisms were devised during the early 1990s and the global positioning system (GPS) constellation was completed at around the same time; with high performance IMUs also commercially available by the mid-1990s, integrated GPS/IMU georeferencing systems were thus able to deliver airborne platform position and altitude data down to a scale of 4-7 $\mathrm{cm}$ (Petrie \& Toth 2009). ALS has developed extremely rapidly and is now in widespread use, with many authors exploring its potential for use in forestry (Naesset 1997, Ackerman 1999, Ziegler et al. 2000). A chronology of such forestry-focused scientific research can be found in Hyyppä et al. (2009).

To determine stand/tree height in intensive forest management a variety of methods are available, whose precision and efficiency are generally well known. The comparative advantage of ALS is the possibility for high automation and of making rapid measurement of time-delay data; the use of such models to derive forest stand/tree parameters should guarantee both precision of results and the avoidance of user error. The main aim of the present paper was to demonstrate the potential for using ALS data of low point density $\left(1\right.$ point per $\left.3 \mathrm{~m}^{2}\right)$. Although the DTM created from these data, particularly those points under canopy cover, was of poor quality, such obstacles can potentially be overcome by the creation of a DTM using additional contour data. The DSM derived from these low point density data was also not of high quality, due to the fact that the tops of tree crowns were less likely to be hit by laser impulses. The raster resolution of both DTMs and the DSM was $8 \mathrm{~m}$, which was the lowest spatial resolution possible for DTM creation from the ALS data without errors. The height of selected forest stands, older than 80 years of age, was determined using mean and maxima functions, with these values then compared with those contained in the current FMP. The results of this comparison revealed that only the use of the mean function was statistically significant, with the ALS-derived heights of stands with density greater than 0.7 similar to FMP values. In contrast, the use of the maxima function is recommended only for forests with low stand density, such as those in which seed trees are employed. The forest stand height obtained using this method with data with low point density has potential for large differences between some observed and modeled values. Thus, it is important to be aware of this when using this obtained forest stand height to assess other forest stand parameters, because of error accumulation in the calculation. There is the possibility to improve the input data for the calculation of other forest stand characteristics, e.g., by using forest inventory data and statistical models (Andersen et al. 2005, Naesset et al.
2005, Hollaus et al. 2009, Clementel et al. 2012). Although some individual results of the present study are similar to those of other authors (Heurich 2008, Wezyk et al. 2008), most are relatively poor.

As stated previously, low point density data should be carefully used for other forest stand parameter derivation. However, the cost of low point density data is less than that of high density data; as such, the former can therefore be used by state agencies or other organizations for forest management practices such as felling control, measurement of disaster area and the detection of gross mistakes in FMP data. Big differences between the forest stand height derived from the ALS data and the height obtained from the FMP were identified in three forest stands in which tree felling was done. The differences were from $77 \%$ to $97 \%$ by height extracted from nDSM_L and from $65 \%$ to $107 \%$ by height extracted from nDSM C. The tree felling was verified on the orthoimages. DTMs employed in forestry must be of good quality, while only DSMs should be created from low point density ALS data. In addition, different respective approaches should be employed for low and high density stands, because - as shown in the present study - no single method was optimal for all stand densities.

\section{Acknowledgments}

This work is the result of the implementation of the project: Centre of Excellence "Decision support in forest and country", ITMS: 26220120069, supported by the Research \& Development Operational Programme funded by the ERDF. The author would also like to thank Geodis Slovakia s.r.o. for providing the ALS data used in this study.

\section{References}

Ackerman F (1999). Airborne laser scanning present status and future expectation. ISPRS Journal of Photogrammetry and Remote Sensing 54: 64-67. - doi: 10.1016/S0924-2716(99)00009 $-\mathrm{X}$

Andersen HE, McGaughey RJ, Reutebuch SE (2005). Estimating forest canopy fuel parameters using LIDAR data. Remote Sensing of Environment 94 (4): 441-449 - doi: 10.1016/j.rse.2004. 10.013

Andersen HE, Breindenbach J (2007). Statistical properties of mean stand biomass estimators in a LIDAR-based double sampling forest survey design. In: Proceedings of the ISPRS Workshop "Laser Scanning 2007 and SilviLaser 2007”. Espoo (Finland), 12-14 September 2007, pp. 8-13. Anderson JE, Plourde LC, Martin ME, Braswell BH, Smith ML, Dubayah RO, Hofton MA, Blair JB (2008). Integrating waveform lidar with hyperspectral imagery for inventory of a northern temperate forest. Remote Sensing of Environment 112 (4): 1856-1870. - doi: 10.1016/j.rse.
2007.09.009

Baltsavias EP (1999). A comparison between photogrammetry and laser scanning. ISPRS Journal of Photogrammetry and Remote Sensing 54: 83 94. - doi: 10.1016/S0924-2716(99)00014-3

Bauerhansl C, Rottensteiner F, Briese C (2004). Determination of terrain models by digital image matching methods. In: Proceedings of the XX ISPRS Congress "Geo-Imagery Bringing Continents”. Istanbul (Turkey) 12-23 July 2004, comm. 4, pp. 414-419.

Bavlšík J, Antal P, Kočik L, Kominka V, Kučera J, Machanský M, Ruman K, Szarka P, Valach L, Zabka L, Duben Z, Rizman I, Šandorfi K, Ziaková M (2008). Work practices of forest management no. A/2008/1611. National Forest Centre, Zvolen, Slovakia. [in Slovakian]

Brandtberg T, Warner TA, Landenberger RE, McGraw JB (2003). Detection and analysis of individual leaf-off tree crowns in small footprint, high sampling density lidar data from the eastern deciduous forest in North America. Remote Sensing of Environment 85 (3): 290-303. - doi: 10.1016/S0034-4257(03)00008-7

Briese C, Pfeifer N, Dorninger P (2002). Applications of the robust interpolation for DTM determination. In: Proceedings of the ISPRS Symposium "Photogrammetric Computer Vision". Graz (Austria), 9-13 September 2002, comm. III, pp. 55-61.

Clementel F, Colle G, Farruggia C, Floris A, Scrinzi G, Torresan CH (2012). Estimating forest timber volume by means of "low-cost" LiDAR data. Italian Journal of Forest Sensing 44: 125 140. - doi: 10.5721/ItJRS201244110

Coops NC, Hilker T, Wulder MA, St-Onge B, Newnham G, Siggins A, Trofymow JA (2007). Estimating canopy structure of Douglas-fir forest stands from discrete-return LiDAR. Trees Structures and Function 21 (3): 295-310. - doi: 10.1007/s00468-006-0119-6

Dean TJ, Cao QV, Roberts SD, Evans DL (2009). Measuring heights to crown base and crown median with LiDAR in mature, even-aged lobolly pine stand. Forest Ecology and Management 257 (1): 126-133. - doi: 10.1016/j.foreco.2008.08. 024

Farid A, Goodrich DC, Sorooshian S (2006). Using airborne lidar to discern age classes of cottonwood trees in a riparian area. Western Journal of Applied Forestry 21 (3): 149-158.

Heurich M (2008). Automatic recognition and measurement of single trees based on data from airborne laser scanning over the richly structured natural forests of the Bavarian Forest National Park. Forest Ecology and Managent 255 (7): 2416-2433. - doi: 10.1016/j.foreco.2008.01.022 Hollaus M, Wagner W, Kraus K (2005). Airborne laser scanning and usefulness for hydrological models. Advances in geosciences 5: 57-63. - doi: 10.5194/adgeo-5-57-2005

Hollaus M, Wagner W, Schadauer K, Maier B, Gabler K (2009). Growing stock estimation for alpine forests in Austria: a robust lidar-based approach. Canadian Journal of Forest Research 39 (7): 1387-1400. - doi: 10.1139/X09-042 
Holmgren J, Nilsson M, Olsson H (2003). Estimation of tree height and stem volume on plots using airborne laser scanning. Forest Science 49 (3): 419 - 428.

Hyyppä J, Hyyppä H, Xiaowei Y, Kaartinen H, Kukko A, Holopainen M (2009). Forest inventory using small-footprint airborne LiDAR. In "Topographic Laser Ranging and Scanning: Principles and Processing" (Shan J, Toth CK eds). CRC Press, Boca Raton, FL, USA, pp. 335 370.

INPHO (2009). DTMaster Manual for Version 5.2 and higher. INPHO GmbH, Stuttgart, Germany.

Jenn DC (2005). Radar and laser cross section engineering $\left(2^{\text {nd }}\right.$ edn $)$. American Institute of Aeronautics and Astronautics, Reston, VA, USA, pp. 505.

Korpela I, Dahlin B, Schäfer H, Bruun E, Haapaniemi F, Honkasalo J, Ilvesniemi S, Kuutti V, Linkosalmi M, Mustonen J, Salo M, Suomi O, Virtanen H (2007). Single-tree forest inventory using LIDAR and aerial images for 3D treetop positioning, species recognition, height and crown width estimation. In: Proceedings of the ISPRS Workshop "Laser Scanning 2007 and SilviLaser 2007". Espoo (Finland) 12-14 September 2007, pp. 227-233.

Liang X, Hyypä J, Matikainen L (2007). Deciduous-coniferous tree classification using difference between first and last pulse laser signatures. In: Proceedings of the ISPRS Workshop "Laser Scanning 2007 and SilviLaser 2007”. Espoo (Finland) 12-14 September 2007, pp. 253257.

Lillesand MT, Kiefer WR, Chipman WJ (2008). Remote sensing and image interpretation $\left(6^{\text {t }}\right.$ edn). John Wiley \& Sons, Hoboken, NJ, USA, pp. 756.

Lim K, Treitz P, Groot A, St-Onge B (2001). Estimation of individual tree heights using LIDAR remote sensing. In: Proceedings of the " $23^{\text {rd }} \mathrm{An}$ nual Canadian Symposium on Remote Sensing". Quebec (QC - Canada), 21-24 August 2001, pp 243-250.

Morsdorf F, Meier E, Kötz B, Itten KI, Dobbertin M, Allgöwer B (2004). LIDAR-based geometric reconstruction of boreal type forest stands at single tree level for forest and wildland fire management. Remote Sensing of Environment 92
(3): 353-362. - doi: 10.1016/j.rse.2004.05.013 Naesset E (1997). Estimating timber volume of forest stands using airborne laser scanner data. Remote Sensing of Environment 61 (2): 246253. - doi: 10.1016/S0034-4257(97)00041-2

Naesset E, Okland T (2002). Estimating tree height and tree crown properties using airborne scanning laser in a boreal nature reserve. Remote Sensing of Environment 79 (1): 105-115. - doi: 10.1016/S0034-4257(01)00243-7

Naesset E, Bollandsås OM, Gobakken T (2005). Comparing regression methods in estimation of biophysical properties of forest stands from two different inventories using laser scanner data. Remote Sensing of Environment 94 (4): 541553. - doi: 10.1016/j.rse.2004.11.010

Naesset E (2009). Effects of different sensors, flying altitudes, and pulse repetition frequencies on forest canopy metrics and biophysical stand properties derived from small-footprint airborne laser data. Remote Sensing of Environment 113 (1): 148-159. - doi: 10.1016/j.rse.2008.09.001

Orka HO, Naesset E, Bollandsås OM (2007). Utilizing airborne laser intensity for tree species classification. In: Proceedings of the ISPRS Workshop "Laser Scanning 2007 and SilviLaser 2007”. Espoo (Finland) 12-14 September 2007, pp. 300-304.

Persson A, Holmgren J, Soderman U, Olsson H, (2004). Tree species classification of individual trees in Sweden by combining high resolution laser data with high resolution near-infrared digitalt images. In: Proceedings of the ISPRS working group VIII/2 "Laser-Scanners for Forest and Landscape Assessment". Freiburg (Germany) 3-6 October 2004, pp. 258-261.

Petrie G, Toth CK (2009). Introduction to laser ranging, profiling, and scanning. In: "Topographic Laser Ranging and Scanning: Principles and Processing" (Shan J, Toth CK eds). CRC Press, Boca Raton, FL, USA, pp. 1-28.

Popescu SC, Zhao K (2008). A voxel-based lidar method for estimating crown base height for deciduous and pine trees. Remote Sensing of Environment 112 (3): 767 - 781. - doi: 10.1016/j. rse.2007.06.011

Salas C, Ene L, Gregoire TG, Naesset E, Gobakken T (2010). Modelling tree diameter from airborne laser scanning derived variables: a comparison of spatial statistical models. Remote Sensing of Environment 114 (6): 1277-1285. doi: 10.1016/j.rse.2010.01.020

Smreček R (2012). Utilization of ALS Data for Forestry Purposes. In: "GI_Forum 2012: Geovisualization, Society and Learning” (Jekel T, Car A, Strobl J, Griesebner G eds). Herbert Wichmann Verlag, VDE Verlag GMBH, Berlin and Offenbach, Germany, pp. 365-376.

Tuček J (2001). Airborne laser scanning as new method for data collecting in forestry. In: "GIS Ostrava 2001". Ostrava (Czech Republic) 21-24 Jan 2001, pp. 13. [in Slovakian] - [online] URL: http://gis.vsb.cz/GIS_Ostrava/GIS_Ova_2001/Sb ornik/default.htm

Wack R, Schardt M, Barrucho L, Lohr U, Oliveira $\mathrm{T}$ (2003). Forest inventory for eucalyptus plantations based on airborne laserscanner data. In Proceedings of the ISPRS working group III/3 workshop "3D reconstruction from airborne laserscanner and InSAR data". Dresden (Germany) 8-10 October 2003, pp. 7.

Wagner W (2010). Radiometric calibration of small-footprint full-waveform airborne laser scanner measurements: basic physical concepts. ISPRS Journal of Photogrammetry and Remote Sensing 65: 505-513. - doi: 10.1016/j.isprsjprs. 2010.06.007

Wagner W, Eberhöfer C, Hollaus M, Summer G (2004). Robust filtering of airborne laser-scanner data for vegetation analysis. In: Proceedings of the ISPRS working group VIII/2 "Laser-Scanners for Forest and Landscape Assessment”. Freiburg (Germany) 3-6 October 2004, pp. 56-61.

Wezyk P, Tompalski P, Szostak M, Glista M, Pierzchalski M (2008). Describing the selected canopy layer parameters of the scots pine stands using ALS data. In: Proceedings of SilviLaser 2008 " 8 th International Conference on LiDAR Applications in Forest Assessment and Inventory". Edinburgh (Scotland) 17-19 September 2008, pp. 636-645.

Ziegler M, Schradt M, Konrad H (2000). Establishing ways of laser scanner data for forest inventory - laser scanning for forest inventory. In: "Application of remote sensing of the Earth in forestry". Zvolen (Slovakia) 12-14 September 2000, pp. 57-64. [in German] 